\title{
Resenhas \\ O silêncio da antiga Musa
}

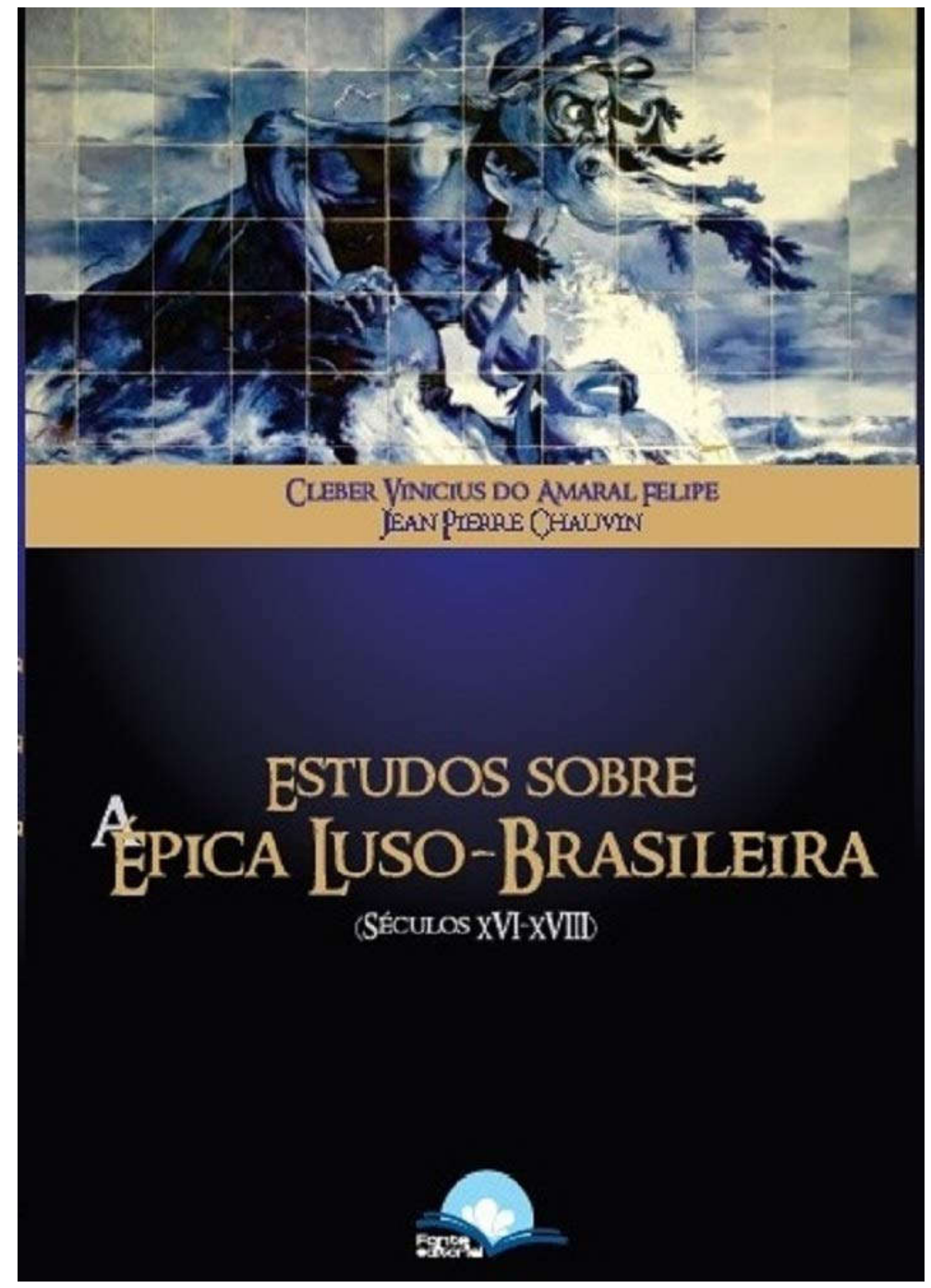

\section{Rodrigo Gomes Oliveira Pinto}

Mestre e doutor em Letras (Literatura Portuguesa) pela Universidade de São Paulo (USP). Professor do Colégio Santa Cruz, em São Paulo. rodrigopinto75@yahoo.com.br 


\section{O silêncio da antiga Musa}

The silence of the ancient Muse

Rodrigo Gomes Oliveira Pinto

FELIPE, Cleber Vinicius do Amaral e CHAUVIN, Jean Pierre. Estudos sobre a épica luso-brasileira (séculos XVI-XVIII). São Paulo: Fonte, 2021, 172 p.

O silêncio da antiga Musa é evocado nos versos finais da proposição de Os lusíadas (1572), de Luís de Camões, a fim de que, cessados os cantos que notabilizaram a fama de heróis como Odisseu ou Eneias, possa ser entoado e ouvido um canto de maior valor, que, com "engenho \& arte", louva as façanhas de "barões assinalados", cujas ações dilataram o império lusitano e a cristandade, nos séculos XV e XVI. O silêncio é conclamação de engrandecimento da matéria camoniana, é locus epidítico que evidencia as práticas compositivas de imitação e de emulação no gênero épico, consoante a autoridade homérica, ao passo que a Musa, filha de Zeus e da Memória, Calíope - posto que presida o gênero em que Camões escreve, mesmo se fosse invocada no poema, e não as fictícias Tágides -, não evoca como nume a verdade de todas as coisas, porque nada anima; ela ornamenta e denota as convenções eruditas de verossimilhança e de adequação da ficção em Os lusíadas, mirando o deleite discreto e a instrução, sempre muito obediente e muito cristã, dos letrados portugueses seiscentistas.

O silêncio da antiga Musa, porém, talvez seja, em conformidade com a leitura marxiana da poesia épica, definitivo; silêncio de morto, indício da impossibilidade da epopeia em sua "forma clássica". São conhecidas as indagações de Karl Marx, nos Manuscritos econômicos de 1857-1858, que inquirem se é possível Aquiles com a pólvora e com o chumbo, se é possível a Ilíada com a prensa e se não desapareceram as condições necessárias à poesia épica, isto é, o canto, os mitos e a Musa, com a alavanca do impressor. Afinal, como escreve Marx: "O que pode Vulcano diante da Roberts \& Co., Júpiter diante do pararaios e Hermes diante do Crédit Mobilier?". ${ }^{1}$ Por certo, é ocioso buscar responder a indagações cujas respostas estão dadas: nada poderia Aquiles contra a pólvora e o chumbo no século XVI, e nada poderia hoje contra as milícias armadas do submundo oficial, assim como nada podem as divindades contra a razão instrumental, quando o capital universaliza a morte e se generaliza na codificação da inteligibilidade das relações sociais e dos usos de linguagem. Ora, como escreve João Adolfo Hansen em "Lendo a épica portuguesa e luso-

\footnotetext{
${ }^{1}$ MARX, Karl. Grundrisse. Manuscritos econômicos de 1857-1858. Esboços da crítica da economia política.
} São Paulo-Rio de Janeiro: Boitempo/Editora UFRJ, 2011, p. 91 e 92. 
brasileira antiga", "desde a Revolução Francesa, o leitor sabe, as virtudes que na épica antiga constituíam a excelência dos varões assinalados foram substituídas pelo how much do valor de troca" (prefácio, p. 9).

As memórias da guilhotina, aprende-se com Georg W. F. Hegel, trouxeram vivências que tornaram insuportável a forma artística épica. Pois o insuportável do gênero e o silêncio do morto, enfrentam-no Cleber Vinicius do Amaral Felipe e Jean Pierre Chauvin no recém-publicado livro Estudos sobre a épica luso-brasileira (séculos XVI-XVIII), neste 2021 brasileiro de barbárie, em que a guilhotina não é memória, e sequer utopia. Agudos leitores, ambos sabem que, embora a Musa nada mais inspire, os usos dos versos de Homero variaram historicamente, e assim também o gênero, desde que a Ilíada e a Odisseia se submeteram aos imperativos da escrita e da leitura, na condição de obras exemplares artisticamente aprazíveis e dignas de imitação para os poetas. E sabem também Felipe e Chauvin, docentes na universidade pública, que o silêncio da antiga Musa não reivindica o silêncio do leitor, de maneira que a recusa desse silêncio, por meio da leitura e da escrita, é a defesa da poesia e da reflexão em tempos de indigência. O livro, com a referida introdução de Hansen e com a contracapa de Mônica Lucas, enlaça, em seis capítulos, estudos que são dedicados aos poemas épicos de seis autores de língua portuguesa. A saber: Os lusíadas, de Luís Vaz de Camões (ca. 1524/25-1580), Naufrágio e lastimoso sucesso da perdição de Manuel de Sousa de Sepúlveda (1594), de Jerônimo Corte-Real (ca. 1530-1588), Ulisseia ou Lisboa edificada (1636), de Gabriel Pereira de Castro (1571-1632), A conquista de Goa (1759), de Francisco de Pina e Melo (1695-1773), O Uraguay (1769), de Basílio da Gama (1741-1795) e, por fim, Caramuru (1781), de Frei José de Santa Rita Durão (1722-1784). Felipe é autor dos três primeiros capítulos que compõem Estudos sobre a épica luso-brasileira, e Chauvin, dos três derradeiros.

No primeiro, intitulado "Camões e a epopeia lusíada: notas introdutórias", Felipe, cioso do enfrentamento dos princípios biográficos que amiúde orientam a leitura de poesia e, ademais, conhecedor dos condicionamentos poéticos e retóricos que instituem as letras quinhentistas em gênero elevado, delineia as escassas notícias sobre o poeta sem positivar imagines e esquadrinha Os lusíadas, apresentando ao leitor a disposição da obra, isto é, o plano que a constitui tal como discriminado pelas disciplinas retórica e poética sabidas do poeta. Camões é, então, pensado tal como em retrato: "tipo aristocrata, católico, letrado e soldado", oriundo de pequena nobreza; "tipo letrado orgulhoso da nobreza e com dificuldades de conceber a riqueza como critério definidor da hierarquia"; "persona discreta, versada nas letras e experimentada nas armas, que se feriu em batalha e cantou, com grandiloquência, os feitos memoráveis dos portugueses". Desses retratos, o leitor não deduz o homem empírico Luís de Camões, mas os valores de uso da auctoritas do poeta. Já a matéria poética de Os lusíadas, pensa-a Felipe como eficazmente ordenada por Camões, em perspectiva da jurisprudência que lhe fornecem poetas como Homero ou Virgílio. Desse modo, o estudo, com a paciência que convém aos estudos introdutórios, dispõe quais sejam as partes do poema - proposição, invocação, dedicatória, narrativa e epílogo -, e por ele conduz o leitor em exposição elucidativa. Dessas partes, Felipe apenas não esquadrinha a narrativa, mesmo que a pressuponha no corpo da argumentação do ensaio e mesmo que com ela dialogue. 
Como pontua Hansen, na abertura do livro, Camões é hoje poeta lembrado e pouco lido - e não raro lido em extratos de uso didático que dão sobrevida ao modo de pensar das histórias literárias, embora sejam incapazes de formar leitores de poesia antiga por alienar os poemas dos pressupostos que lhe orientavam as maneiras de fazer. Caso algo distinto é o de Jerônimo CorteReal, "nunca lido e esquecido", cuja poesia é matéria do segundo capítulo do livro, "A poesia épica e a experiência trágica: o naufrágio de Sepúlveda". Neste capítulo, Felipe indaga a hipótese de que Jerônimo Corte-Real tenha composto uma epopeia trágica e investiga as delimitações que circunscrevem o gênero épico. O ensaio, para tanto, pensa as articulações discursivas que há entre o poema Naufrágio e lastimoso sucesso da perdição de Manuel de Sousa de Sepúlveda e as relações de naufrágio recolhidas na História trágico-marítima (1735-1736), de Bernardo Gomes de Brito, de sorte a evidenciar as distinções entre o discurso da história (e de seus subgêneros) e o discurso da poesia no século XVI, e pensa sobretudo os atravessamentos trágicos no poema heroico de Corte-Real, compostos para afetar o leitor quinhentista por meio do terror e da piedade. Dedicando-se a esses atravessamentos e, ademais, rechaçando leituras que pensam a poesia como reflexo das realidades empíricas ou como figuração íntima do poeta, Felipe contradita análises anacrônicas de CorteReal, que leem como indícios de decadência ou de pessimismo os procedimentos de efetuação trágica empregados no poema. O capítulo mostra, enfim, que os infortúnios trágicos, sendo condizentes com os protocolos do epos e com os usos poéticos consagrados, podem instruir e deleitar, porque devem ser tomados como matéria infeliz forjada com arte, apta a conferir variedade decorosa ao gênero. Como epopeia trágica, enfim, o Naufrágio de Sepúlveda definese pela imitação não da coisa bélica, mas das ações de personagens caracterizadas como virtuosas e graves.

O último ensaio de autoria de Felipe intitula-se "A fundação épica de Lisboa na Ulisseia (1636), de Gabriel Pereira de Castro". Recordando a exemplaridade da Eneida, como obra que narra a fundação mítica de Roma e faz a exaltação de Augusto (séc. I a.C.), e assumindo a prática imitativa no gênero épico, sempre à luz de Homero, Felipe dedica-se, nesse capítulo, ao estudo da Ulisseia ou Lisboa edificada. Trata-se de poema de impressão póstuma, dedicado a Filipe IV de Espanha em tempos de União Ibérica, em cuja narrativa a errância de Ulisses, após a queda de Troia, ganha a injunção dos fados: antes de regressar a Ítaca, deve o herói, navegante impetuoso, fundar Lisboa. Como nos capítulos anteriores, Felipe percorre, analiticamente, o título, a proposição, a invocação e a elocução do poema de Gabriel Pereira de Castro, a fim de explicitar como a imitação e a emulação, na medida em que sejam compreendidas como procedimentos eletivos, estribam as práticas de composição da Ulisseia ou Lisboa edificada. Isso permite ao estudo rechaçar o rótulo "barroco" que etiquetou o poema ao longo do século XX e desfazer a pecha de servilismo atribuída ao poeta, a qual costuma esquecer que a originalidade é mercadoria burguesa. Ressaltam no estudo de Felipe as análises dos expedientes elocutivos que amplificam no poema as descrições das tempestades que infortunam e aterrorizam a viagem fatídica de Ulisses, pensadas em visada comparativa que lê descrições assemelhadas, em registro elevado, em Ovídio, em Homero e em Camões. Destaca-se também o exame do formidável Hércules, gigante qual Adamastor, surgido no Canto V da Ulisseia ou Lisboa edificada. Felipe 
examina-o ao investigar a hipótese de que Gabriel Pereira de Castro figure, por meio do poema, não a virtude da prudência, virtude pela qual Ulisses se notabiliza em Homero, mas o ímpeto virtuoso, livre de ambição e de cobiça, por afrontar mares nunca dantes navegados. Num e noutro caso, observa-se que é sempre oportuna a mobilização de lugares-comuns quando a poesia é retoricamente pensada.

Com tal estudo de Felipe, encerra-se a porção do livro que lê obras de autores lusitanos quinhentistas e seiscentistas. Os demais capítulos projetamse em direção ao século XVIII. No capítulo "A conquista de Goa, exercício poéti$\mathrm{Co}^{\prime \prime}$, Jean Pierre Chauvin estuda o poema épico de Francisco de Pina e Melo, pensando-o como obra que opera com eficácia os preceitos do gênero. Poeta mal lido, quando lido, como indica Chauvin, por categorias analíticas teleológicas, evolucionistas e anacrônicas que incompreendem as convenções poéticas e retóricas que lhe orientam as maneiras de escrever, Pina e de Melo é autor de extensos escritos que teorizam o fazer poético, como a Arte poética (1765) ou como o "Prolegômeno para a boa inteligência, conhecimento do poema", que prefacia o poema épico-polêmico Triunfo da religião (1756). Chauvin lê o "Da epopeia", texto prefacial de A conquista de Goa, de modo a examinar como, sabedor das preceptivas, o poeta as opera, mirando o deleite instrutivo de leitores discretos, a saber, aqueles capazes de reconhecer o bom uso dos procedimentos técnicos empregados na composição poética. Mais: Chauvin faceia a persona fingida pelo poeta, desembaraçando-a, como ficta, do homem letrado Francisco de Pina e Melo, e lembrando, ainda - o que nunca é demais lembrar -, que aqui a poesia é artifício que deve passar por natureza. Essa persona invoca a inspiração da "divina Inteligência" - a supor, quiçá, o decoroso silêncio da Musa - e exibe a sujeição ao monarca D. José I, com o propósito de compor um relato encomiástico, em estilo elevado, das vitórias dos portugueses liderados por Afonso Albuquerque contra o domínio muçulmano em Goa, no século XVI. Destrinçando episódios do poema, Chauvin intenta mostrar que o argumento central da fábula de Pina e Melo estabelece a articulação entre o fundamento teológico da empresa lusitana no Oriente, devotada à propagação da fé, e o interesse político que conduz a expansão do império português, em busca de vultosos ganhos econômicos. Depreende-se do capítulo, ao fim, que o epos, já que forja as memórias das façanhas heroicas do passado, traz instrução para o momento presente setecentista em que o poema é escrito e estampado, qual seja, a lição do virtuoso entrelaçamento entre os interesses da monarquia lusitana e os da religião católica, lição que, mirando interceder pelo bem comum, é muito humildemente destinada a D. José I e aos destinatários discretos de A conquista de Goa.

O quinto capítulo intitula-se "Lei, argumento e arte n'O Uraguay". Ele se abre com um proêmio que esquematiza o que Chauvin apresenta como o habitual das leituras das letras luso-brasileiras dos séculos XVI, XVII e XVIII: vigora ora a presunção da sinceridade dos autores e a compreensão de que a poesia, porque sincera, revele a personalidade do sujeito empírico que a compõe, deixando vazar traços biográficos ou servindo de fonte para a escrita biográfica; vigora ora mesmo a crença na autenticidade das ações figuradas nos poemas, compreendidos, então, como documentos de factualidade positiva. Em contraposição a esses princípios, de que decorre, por vezes, a irrestrita desistoricização das maneiras de fazer poesia, Chauvin recorda que as letras 
luso-brasileiras desse tempo demandam pressupostos de leitura que, abdicando da sinceridade ou da autenticidade, considerem a materialidade dos suportes e dos meios pelos quais circulam, e que também as assumam como artefatos convencionados de linguagem, cuja compreensão (possível) seja conforme a variedade e a multiplicidade dos atos de produção e de destinação em que estão inscritas, segundo os preceitos de imitação e os gêneros retóricopoéticos conhecidos por esses autores. Em torno de tais pressupostos, convém acrescentar, coadunam-se os trabalhos de Chauvin e de Felipe ao longo de todo o livro. E, com base neles, Chauvin lê O Uraguay. Sobressaem nessa leitura as articulações políticas que o estudo explicita entre a obra épica de Basílio da Gama, o Tratado de Madri (1750), o Diretório dos índios (1767) e a Lei da boa razão (1769), que mostram como o poema incorpora o ordenamento jurídico que lhe é coetâneo. No mais, Chauvin trata de iterar como é improdutiva a insistência no discurso nacionalista que lê e treslê O Uraguay - não sem muitos lamentos -, desde o século XIX.

O derradeiro capítulo incursiona pela "Revisão do Caramuru". Interessado em deslindar e em reiterar os pressupostos de trabalho com as letras luso-brasileiras afirmados no capítulo anterior, Chauvin redige um estudo dividido em três partes que recordam três das partes da retórica - invenção, disposição e elocução. Nesses passos, revisita as leituras de Caramuru, desde Ferdinand Denis (1826), indaga as razões da insistência no discurso nacionalista nas leituras de muitos estudiosos brasileiros que se propuseram a pensar o poema e percorre distintos episódios da fábula que compôs o Frei José de Santa Rita Durão, com o intuito de evidenciar como o Caramuru, composto por um súdito do Reino, numa sociedade de Antigo Regime, pauta-se pelas convenções então consagradas de escrita do poema épico. O capítulo arremata o livro, ajudando o leitor a lembrar o que está posto muito precisamente já na introdução de Hansen e nos estudos que a sucedem: a poesia épica, desde Homero, e até o desmembramento e a liquidação das doutrinas poéticas e retóricas, entre os fins do século XVIII e os princípios do século XIX, não deve ser considerada como categoria de pensamento de validade universal, senão como convenção dedicada a prescrever modos de fazer poesia que assume valores de uso historicamente cambiáveis e instáveis na longa duração de composição do gênero. Felipe e Chauvin, ao fim e ao cabo, ensinam que há usos oportunos e discursivamente circunstanciados dos procedimentos de produção do poema épico, entre os séculos XVI, XVII e XVIII; esses usos são particulares, autorizados pela consuetudo e atualizados por inúmeros letrados, eruditos, tratadistas e poetas, muitos dos quais escritores de língua portuguesa, nos dois lados do Atlântico.

Enfim, desse percurso de enfrentamento do silêncio da antiga Musa, só é possível concluir que os estudos de Felipe e de Chauvin devem ser lidos pelo vigor e pela acuidade com que desenredam a matéria épica. Todavia, uma eventual segunda edição de Estudos sobre a épica luso-brasileira (séculos XVI-XVIII), tanto desejável como necessária, precisa corrigir as muitas gralhas que escaparam aos autores e aos revisores.

Resenha recebida em 31 de março de 2021. Aprovada em 28 de abril de 2021. 